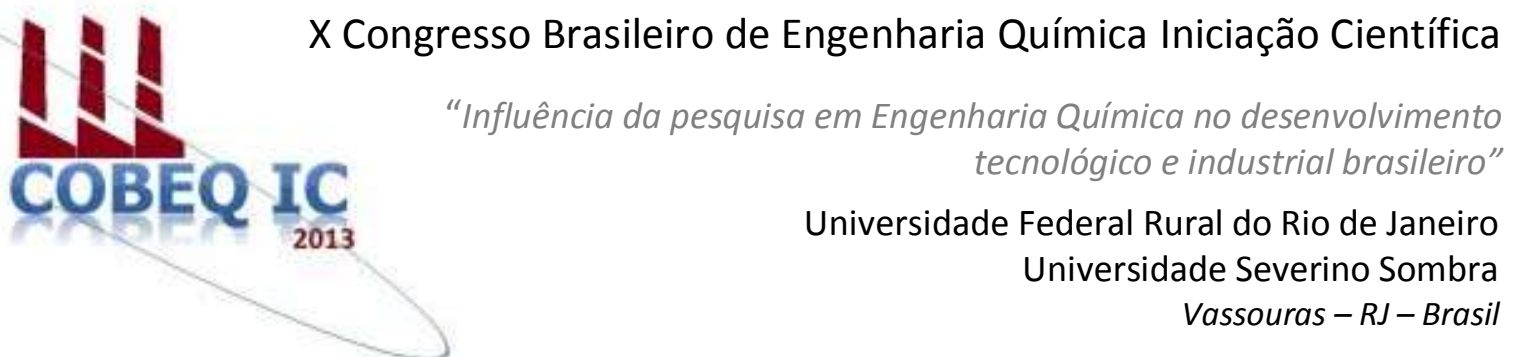

\title{
AVALIAÇÃO DO DESEMPENHO DO SISTEMA DE BIORREATORES HÍBRIDOS SEQUENCIAIS NA REMOÇÃO DE CARBONO ORGÂNICO TOTAL (COT) DE MEIO SINTÉTICO CONTENDO CROMO
}

\author{
F.A Lima ${ }^{1}$; G.M Alves ${ }^{2}$; C.A Brandão ${ }^{3}$, M. M. de Resende ${ }^{4}$; V.L Cardoso ${ }^{4}$ \\ (1) Bolsista de Iniciação Científica - PIBIC/Fapemig/UFU; \\ ${ }^{(2)}$ Bolsista - PIBIT IT-CNPq \\ ${ }^{(3)}$ Bolsista do programa de pós-graduação em Engenharia Química PPGEC/CNPQ; \\ ${ }^{(4)}$ Docentes - FEQ/UFU
}

Faculdade de Engenharia Química, Universidade Federal de Uberlândia. Av João Naves de Ávila, 2121, Bloco 1K, Campus Santa Mônica, Uberlândia - MG, CEP 38408-100 - e-mail:

mresende@feq.ufu.br

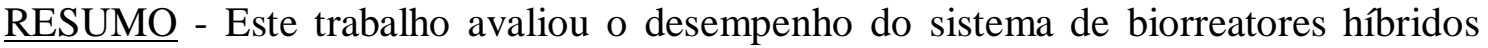
sequenciais, sem aeração e com aeração intermitente, na remoção de Carbono Orgânico Total (COT) de um meio sintético contendo Cr (VI). Como inóculo, foi utilizada uma cultura mista de micro-organismos, previamente adaptada ao cromo, e como fonte de $\mathrm{Cr}$ (VI), o dicromato de potássio. Inicialmente foi realizado um teste de referência (em branco), antes da adição de cromo ao sistema, com o propósito de verificar a influência da presença do metal na remoção da matéria orgânica. Em seguida, foram realizados dois experimentos com o meio sintético (afluente) contendo $\mathrm{Cr}$ (VI) nas concentrações de 80 e $120 \mathrm{mg} / \mathrm{L}$. Após a estabilização do sistema, avaliou-se a remoção de COT durante a regeneração dos biorreatores, com o mesmo meio, porém sem cromo. A caracterização em relação ao Carbono Orgânico Total (COT) foi realizada pela técnica de combustão catalítica a alta temperatura, empregando o aparelho analisador TOCVCPH-ASI+TNM-1 da Shimadzu. No teste de referência, a remoção de COT alcançada foi de $64 \%$. Nos experimentos contendo cromo no meio, as eficiências de remoção foram em torno de $55 \%$ ( $80 \mathrm{mg} / \mathrm{L})$ e $40 \%$ (120 mg/L).
\end{abstract}

Palavras chave: cultura mista, matéria orgânica, bioacumulação.

\section{INTRODUÇÃO}

A aferição do teor de matéria orgânica presente nas águas naturais efetua-se, além da avaliação da Demanda Bioquímica de Oxigênio (DBO) e da Demanda Química de
Oxigênio (DQO), também por intermédio do Carbono Orgânico Total (COT).

A análise de COT considera as parcelas biodegradáveis e não biodegradáveis da matéria orgânica, não sofrendo interferência de outros átomos que estejam ligados à estrutura 
orgânica, quantificando apenas o carbono presente na amostra, sendo dessa forma um indicador útil do grau de poluição do corpo hídrico. O carbono orgânico presente em águas doces origina-se da matéria viva e também como componente de vários efluentes e resíduos, e sua importância ambiental deve-se ao fato de servir como fonte de energia para bactérias e algas, além de complexar metais. A parcela formada pelos excretos de algas cianofíceas pode, em concentrações elevadas, tornar-se tóxica, além de causar problemas estéticos (CETESB, 2009).

A remoção de matéria orgânica ocorre primeiramente pela adsorção na superfície dos flocos microbianos. Em seguida, o poluente é transformado, através de reações de hidrólise ou outras envolvendo enzimas catalíticas, podendo então ser absorvido e metabolizado pela população microbiana. No interior das células, as moléculas absorvidas podem se inserir nas rotas de catabolismo, que geram energia para as atividades celulares ou nas rotas de anabolismo, responsáveis pela biossíntese das moléculas, essenciais ao funcionamento da célula (SANT'ANNA JR., 2010).

Muitos efluentes industriais, tais como aqueles provenientes de fábricas de curtumes e indústrias de processamento de madeira, contêm alto teor de matéria orgânica juntamente com $\mathrm{Cr}$ (VI). Nestes casos, os sistemas de tratamento convencionais não funcionam com eficiência. Desse modo, faznecessário o desenvolvimento de um sistema biológico de tratamento viável para o tratamento de tais águas residuais. No entanto, existem muito poucos estudos sobre sistemas biológicos disponíveis que consigam remover simultaneamente a matéria orgânica e reduzir o $\mathrm{Cr}$ (VI) a Cr (III) (ELANGOVAN e PHILIP, 2009).

Os processos biológicos de tratamento podem ser classificados de acordo com a localização da biomassa dentro do ambiente reacional, dividindo-se em dois grandes grupos, sendo estes: processos com biomassa em suspensão e processos com biomassa fixa. A junção dos mesmos dá origem a um terceiro grupo, conhecido como sistema híbrido, o qual agrega as vantagens inerentes aos dois (MÜLLER, 1998; GEBARA 1999).
Os biorreatores híbridos são caracterizados por conter biomassa fixa e em suspensão em um mesmo volume reacional. Nesse tipo de sistema são utilizados materiais suportes de elevada superfície específica para o crescimento bacteriano, visando agregar as vantagens do sistema de lodo ativado (biomassa floculada) e do biofilme (biomassa fixa) (WOLFF, 2004).

Nesse sentido, o objetivo do presente trabalho foi avaliar o desempenho do sistema de biorreatores híbridos sequenciais, sem aeração e com aeração intermitente, na remoção de Carbono Orgânico Total (COT) de um meio sintético, contendo $6 \mathrm{~g} / \mathrm{L}$ de acetato de sódio, $1 \mathrm{~g} / \mathrm{L}$ de cloreto de amônio e $\mathrm{Cr}$ (VI) nas concentrações de 80 e $120 \mathrm{mg} / \mathrm{L}$. Após a estabilização do sistema, avaliou-se a remoção durante a regeneração dos biorreatores, com o mesmo meio, mas na ausência de cromo. Os ensaios foram comparados ao teste de referência.

\section{METODOLOGIA}

\section{Sistema Experimental Utilizado}

Como inóculo para os biorreatores, foram utilizadas amostras de microorganismos obtidas do lodo de uma indústria de curtume localizada na cidade de Franca (SP), cultivadas, incialmente, por 90 dias em meio de cultura sem $\mathrm{Cr}$ (VI), descrito na Tabela 1. Em seguida, procedeu-se à adaptação dos micro-organismos ao meio contendo o metal, nas concentrações de 40 e $80 \mathrm{mg} / \mathrm{L}$, por 60 dias. Como fonte de cromo hexavalente foi usado o dicromato de potássio $\left(\mathrm{K}_{2} \mathrm{Cr}_{2} \mathrm{O}_{7}\right)$. Após esse período, obteve-se 15 litros de biomassa.

Tabela 1 - Composição do meio de cultura

\begin{tabular}{|c|c|}
\hline Componentes & Concentração (g/L) \\
\hline $\mathrm{NH}_{4} \mathrm{Cl}$ & 1,0 \\
\hline $\mathrm{K}_{2} \mathrm{HPO}_{4}$ & 0,5 \\
\hline $\mathrm{FeSO}_{4 .} .7 \mathrm{H}_{2} \mathrm{O}$ & 0,001 \\
\hline $\mathrm{MgSO}_{4} .7 \mathrm{H}_{2} \mathrm{O}$ & 0,2 \\
\hline $\mathrm{CaCl}_{2} \cdot 2 \mathrm{H}_{2} \mathrm{O}$ & 0,001 \\
\hline $\mathrm{CH}_{3} \mathrm{COONa} .3 \mathrm{H}_{2} \mathrm{O}$ & 6,0 \\
\hline Extrato de Levedura & 0,5 \\
\hline
\end{tabular}


O sistema utilizado, em escala piloto, consistiu em um biorreator híbrido sem aeração seguido por outro com aeração intermitente. Os biorreatores apresentam como característica em comum o fato de operarem com fluxo ascendente, além do diâmetro e altura, iguais a $16,5 \mathrm{~cm}$ e $60 \mathrm{~cm}$, respectivamente. Os biorreatores foram confeccionados em tubos de acrílico e como material suporte foram utilizados partículas cilíndricas de polipropileno, com diâmetro de $3,5 \mathrm{~mm}$ (biorreator sem aeração), e anéis de silicone, com diâmetro de 11,20 mm (com aeração intermitente). Os volumes úteis dos biorreatores, após preenchimento com material suporte, foram de 5,5 L para o primeiro reator e 6,6 L para o segundo. A vazão de alimentação utilizada foi de $4 \mathrm{~mL} / \mathrm{min}-0,3$ $\mathrm{L} / \mathrm{h}$, que corresponde a um tempo de detenção hidráulico total de 48 horas.

A Figura 1 mostra o sistema experimental utilizado, detalhando seus componentes. As amostras foram coletadas em três pontos distintos do sistema, sendo estes: entrada e saída do biorreator sem aeração e saída do biorreator aerado.

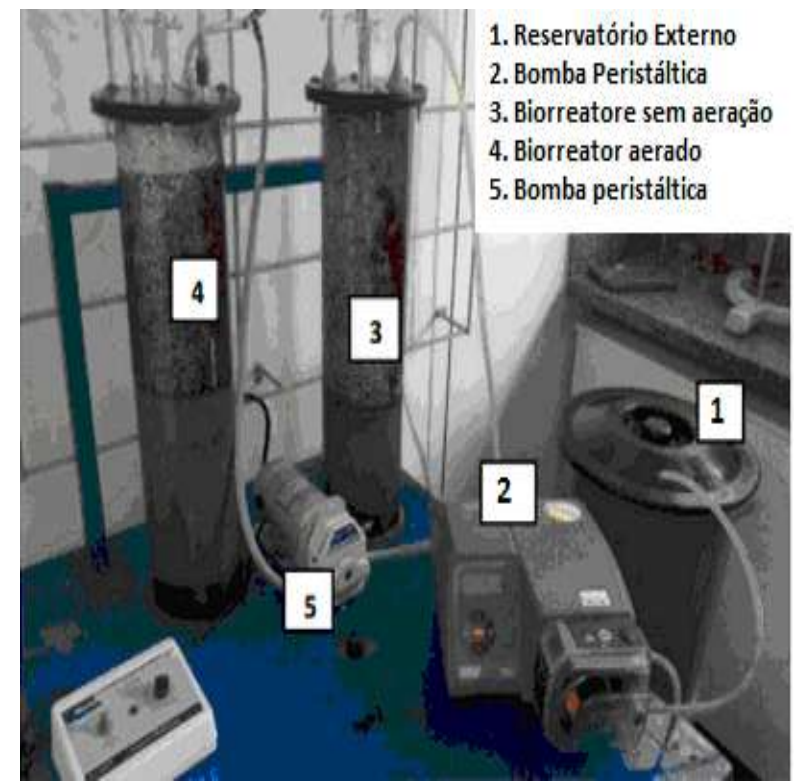

Figura 1 - Sistema Experimental Utilizado

\section{Preparação do inóculo}

Após o término da etapa de adaptação dos micro-organismos, o volume de biomassa obtido foi imediatamente introduzido nos biorreatores, por bombeamento, e permaneceu dentre destes por 30 dias, com a alimentação do meio de cultura, sem cromo, feita por seringas, com o propósito de garantir a fixação dos micro-organismos ao material suporte para formação do biofilme. Nesse período, e durante os experimentos, utilizou-se aeração intermitente no segundo biorreator, na vazão de $20 \mathrm{~mL} / \mathrm{min}$, quatro vezes ao dia por 30 minutos.

\section{Teste de Referência}

Foi realizado um teste de referência (teste em branco) com o meio de cultura descrito na Tabela 1, mas na ausência de $\mathrm{Cr}$ (VI), para se verificar a influência da presença de cromo na remoção da matéria orgânica. $\mathrm{O}$ teste foi feito antes da entrada do meio sintético contendo cromo no sistema e logo após 30 dias da inoculação dos microorganismos, período este que correspondeu à aderência da biomassa ao material suporte dos biorreatores, para a formação do biofilme. Assim, comparou-se a remoção de COT alcançada neste teste, com a remoção obtida nos experimentos contendo cromo.

\section{Remoção de COT}

Foram realizados dois experimentos, um com a concentração inicial de $80 \mathrm{mg} / \mathrm{L}$ e outro, na sequencia, com a concentração de $120 \mathrm{mg} / \mathrm{L}$ de Cr (VI) no meio. Em ambos, a remoção de COT foi avaliada até se atingir o tempo de saturação dos biorreatores, isto é, quando a concentração de cromo na saída dos mesmos se torna igual à concentração na entrada do sistema. Após cada experimento, foi feita a regeneração dos biorreatores, utilizando o mesmo meio, porém sem cromo, onde também foi avaliada a remoção de COT.

A concentração de biomassa nos biorreatores foi medida através da análise dos Sólidos Voláteis em Suspensão (SSV), assim como a viabilidade celular, pelo método de Plaqueamento, em amostras coletadas em pontos intermediários (centrais) dos biorreatores.

\section{Métodos Analíticos}

A caracterização em relação ao Carbono Orgânico Total (COT) foi realizada 
pela técnica de combustão catalítica a alta temperatura, empregando o aparelho analisador TOC-VCPH-ASI+TNM-1 da Shimadzu.

A análise dos Sólidos Voláteis em Suspensão (SSV) foi realizada pelo método dos Sólidos Fixos e Voláteis inflamados a $550^{\circ} \mathrm{C}$, descrito por APHA (2005). O Plaqueamento, ou contagem de microorganismos viáveis, foi realizado pelo método de semeadura em profundidade ("pour plate").

\section{RESULTADOS E DISCUSSÕES}

\section{Teste de referência}

Este experimento durou 144 horas, instante em que se verificou que remoção de COT não variava mais com o tempo. A Figura 2 mostra a remoção de COT obtida no teste em branco.

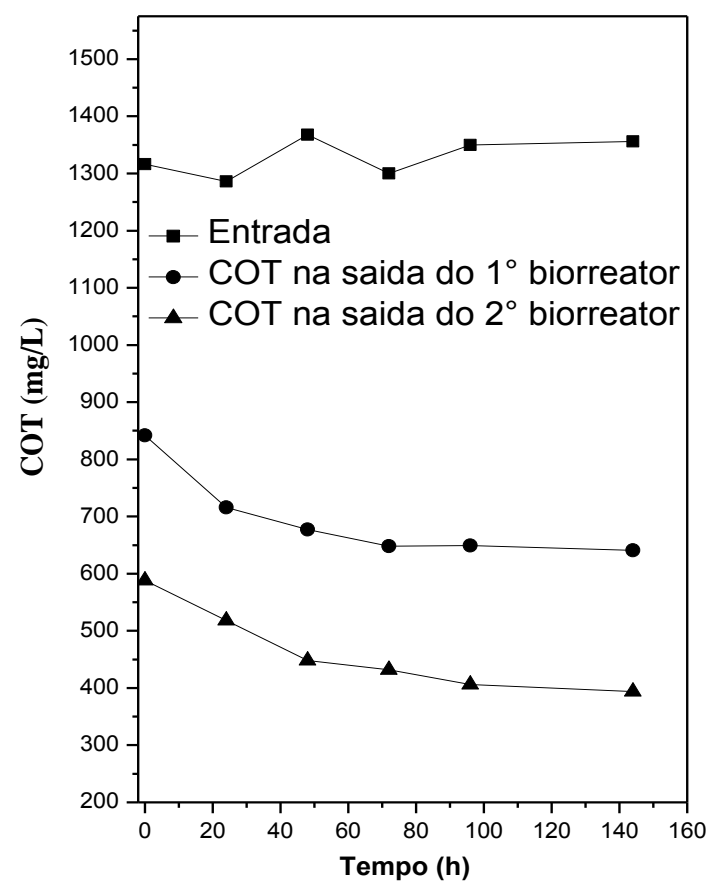

\section{Figura 2 - Remoção de COT no teste em branco}

A concentração média de COT no meio sintético foi $1330 \mathrm{mg} / \mathrm{L}$, sendo que as concentrações, ao final do experimento, nas saídas dos biorreatores, sem aeração e com aeração intermitente, foram iguais a $641 \mathrm{mg} / \mathrm{L}$ e $394 \mathrm{mg} / \mathrm{L}$, respectivamente. Desse modo, a remoção média do primeiro biorreator foi de
$47 \%$, enquanto que a do segundo foi de $32 \%$. A remoção média global de COT foi de $64 \%$.

\section{Concentração inicial de 80 mg/L de Cr (VI)}

A Figura 3 mostra a remoção de Carbono Orgânico Total (COT) no primeiro experimento na presença de cromo $(80 \mathrm{mg} / \mathrm{L})$. A concentração média de COT no meio sintético (entrada do sistema) foi de 1320 $\mathrm{mg} / \mathrm{L}$. As concentrações nas saídas dos biorreatores, no tempo inicial, referem-se às concentrações finais do experimento em branco.

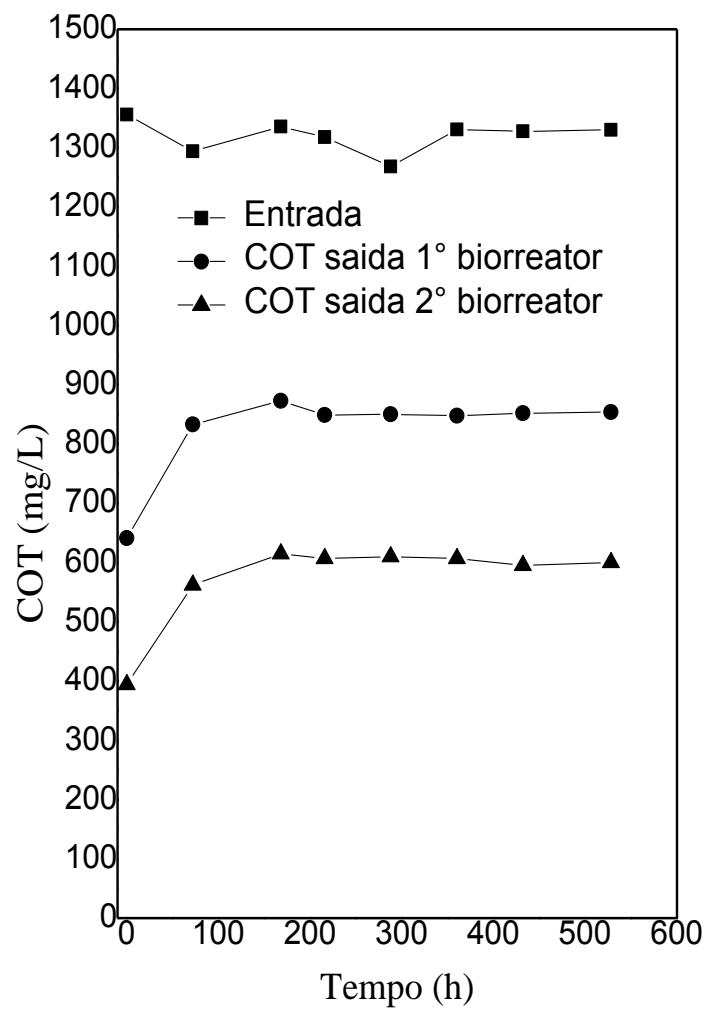

\section{Figura 3 - Remoção de COT durante o ensaio contendo $80 \mathrm{mg} / \mathrm{L}$ de $\mathrm{Cr}$ (VI).}

A concentração de COT na saída dos dois biorreatores aumentou gradativamente nas 170 horas iniciais. A concentração inicial de biomassa no biorreator sem aeração foi de $3500 \mathrm{mg} / \mathrm{L}$, enquanto que no biorreator aerado esta foi de $2500 \mathrm{mg} / \mathrm{L}$ de SSV. A concentração de SSV nos dois biorreatores diminuiu durante as 240 horas iniciais, chegando a $1140 \mathrm{mg} / \mathrm{L}$ no primeiro biorreator, e a $1500 \mathrm{mg} / \mathrm{L}$ no segundo biorreator, permanecendo, em média, próxima a estes valores até o final do experimento. O Plaqueamento realizado no início do experimento mostrou uma 
quantidade de micro-organismos na ordem de $10^{8}$ células $/ \mathrm{mL}$, nas amostras dos dois biorreatores. Após o experimento, a contagem caiu para a ordem de $10^{6}$ células $/ \mathrm{mL}$. Tal situação mostra que o metabolismo da cultura mista esteve voltado para a remoção do cromo, o que ocasionou a perda de micro-organismos durante o intervalo de tempo em questão. Após 220 horas, observa-se a estabilização na remoção, com a concentração de COT em torno de $850 \mathrm{mg} / \mathrm{L}$ e $604 \mathrm{mg} / \mathrm{L}$, nas saídas do biorreator sem aeração e do biorreator aerado, respectivamente. A eficiência média de remoção de COT no biorreator sem aeração, foi de $37,5 \%$, enquanto que no biorreator aerado foi de $30,2 \%$. A eficiência média global foi de $55,8 \%$.

A Figura 4 mostra a remoção de COT durante a regeneração.

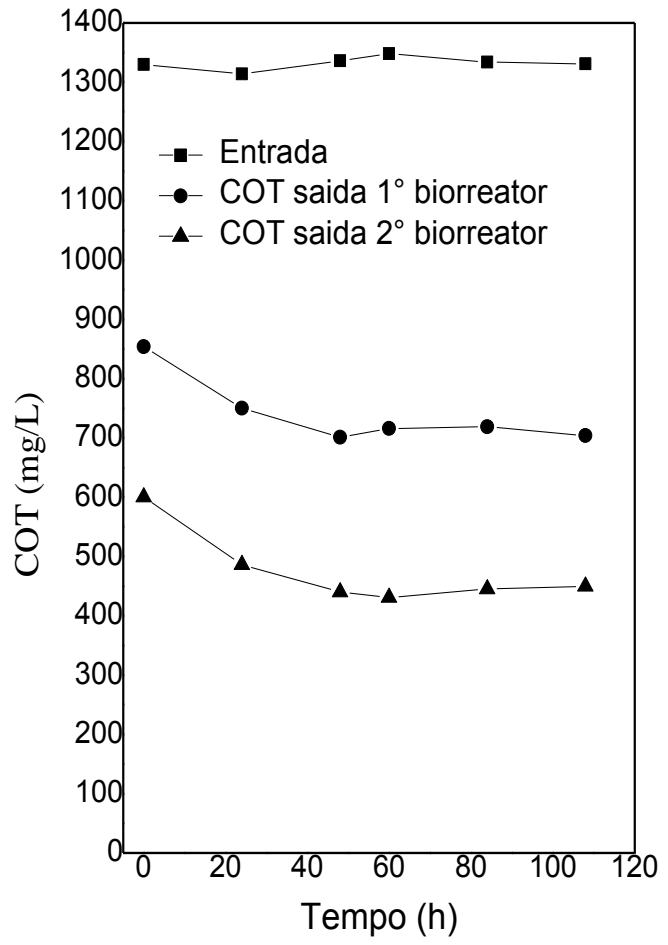

Figura 4 - Remoção de COT durante a regeneração após o experimento com 80 mg/L de Cr (VI).

$\mathrm{Na}$ regeneração, a concentração de COT no primeiro biorreator diminui nas primeiras 48 horas, chegando ao valor de 701 $\mathrm{mg} / \mathrm{L}$, estabilizando-se em torno de $713 \mathrm{mg} / \mathrm{L}$, o que corresponde a uma remoção média de 44,3\%. Já para o segundo biorreator, a concentração de COT decaiu até 60 horas, estabilizando-se no valor de $440 \mathrm{mg} / \mathrm{L}$ até o final, representando uma remoção média de $36 \%$. A remoção média total de COT neste caso foi de $64 \%$. A concentração de biomassa aumentou, chegando a $2500 \mathrm{mg} / \mathrm{L}$ no primeiro biorreator e a $2600 \mathrm{mg} / \mathrm{L}$ no segundo, após o final da regeneração, em 132 horas.

\section{Concentração inicial de $120 \mathrm{mg} / \mathrm{L}$ de $\mathrm{Cr}$ (VI)}

A remoção de Carbono Orgânico Total (COT) durante o experimento com $120 \mathrm{mg} / \mathrm{L}$ de $\mathrm{Cr}$ (VI) no meio é apresentada na Figura 5. A concentração média de COT no meio sintético foi igual a $1395 \mathrm{mg} / \mathrm{L}$.

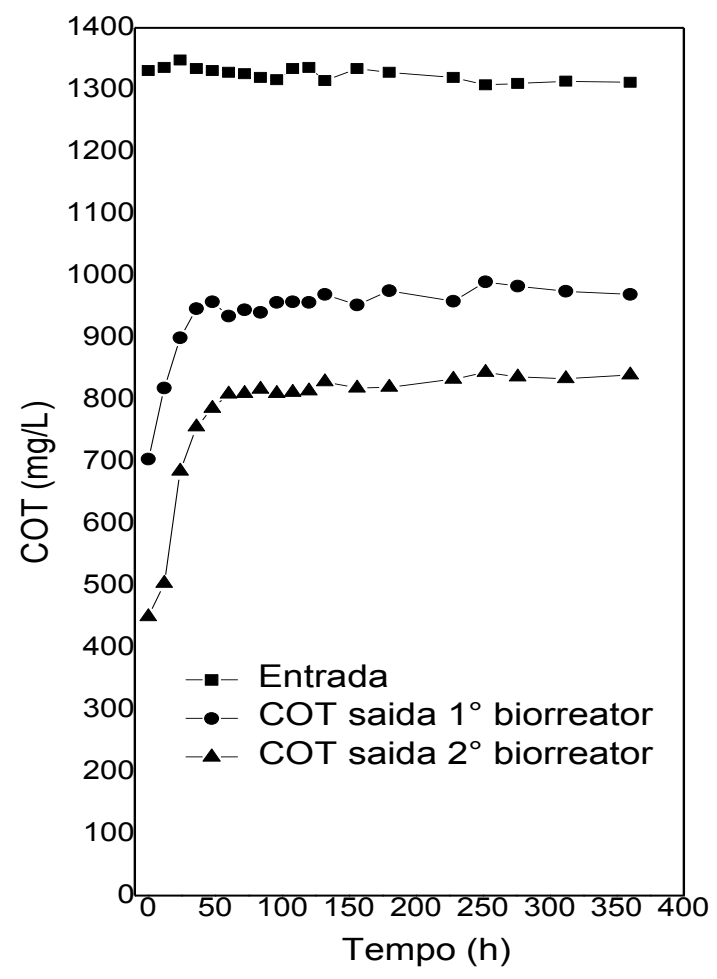

Figura 5 - Remoção de COT durante o ensaio contendo $120 \mathrm{mg} / \mathrm{L}$ de $\mathrm{Cr}$ (VI).

A concentração de COT na saída do biorreator sem aeração aumentou nas 48 horas iniciais, analogamente ao experimento anterior, estabilizando a partir desse instante em torno de $960 \mathrm{mg} / \mathrm{L}$, até o final do experimento. Já na saída do biorreator aerado, a concentração de COT aumentou nas primeiras 72 horas de operação, estabilizando em cerca de $830 \mathrm{mg} / \mathrm{L}$, após esse tempo. A concentração de SSV, nos dois biorreatores, decresceu nas 48 horas iniciais do experimento, aumentando após esse instante e permanecendo praticamente estável, em 2150 $\mathrm{mg} / \mathrm{L}$ no biorreator sem aeração e em 2560 
$\mathrm{mg} / \mathrm{L}$ no biorreator aerado. O Plaqueamento mostrou uma quantidade de micro-organismos viáveis na ordem de $10^{6}$ células $/ \mathrm{mL}$ nos dois biorreatores, no início do experimento (que corresponde ao final do experimento com 80 $\mathrm{mg} / \mathrm{L})$ e de $10^{5}$ células $/ \mathrm{mL}$ ao final deste, indicando, novamente, morte de biomassa

A eficiência média de remoção de COT no biorreator sem aeração, foi de $28,3 \%$, enquanto que no biorreator aerado foi de 17,3\%. A eficiência média global foi de $41,3 \%$.

A Figura 6 mostra a remoção de COT na regeneração. A concentração de COT na saída do primeiro biorreator diminuiu até o final da regeneração, chegando ao valor de 784 $\mathrm{mg} / \mathrm{L}$, com uma remoção média de $13,9 \%$. Já para o segundo biorreator, a concentração de COT também decaiu gradativamente até o fim da regeneração, chegando ao valor de 620 $\mathrm{mg} / \mathrm{L}$, representando uma remoção média de $17 \%$. A remoção média total de COT foi de $46 \%$. A concentração de SSV aumentou pouco, chegando a $2350 \mathrm{mg} / \mathrm{L}$ no biorreator sem aeração e a $2800 \mathrm{mg} / \mathrm{L}$ no biorreator aerado, ao término da regeneração.

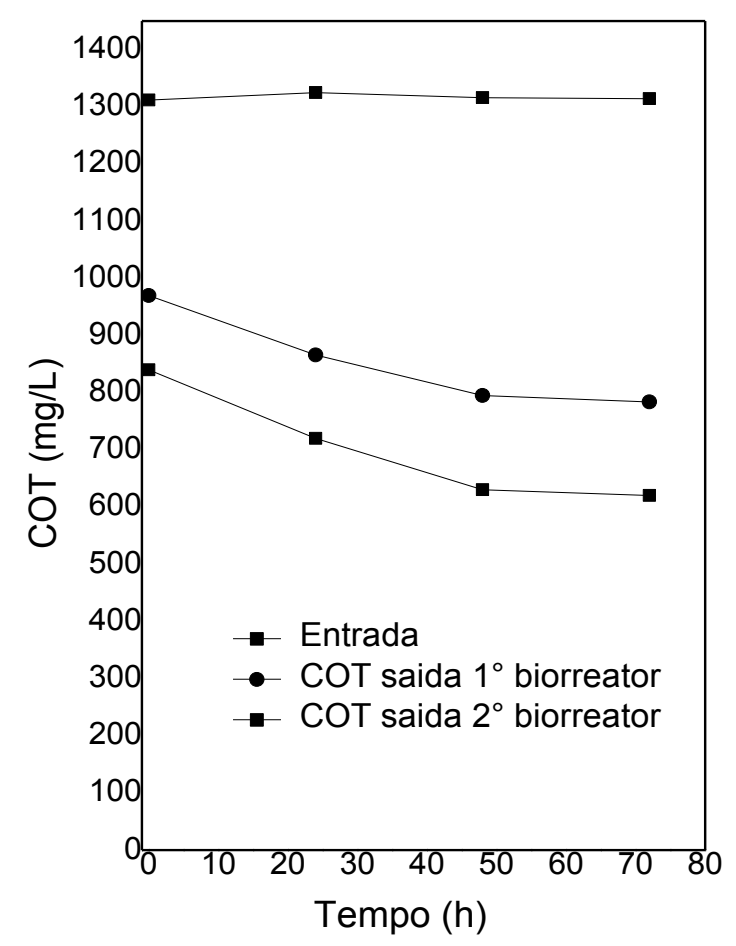

Figura 4 - Remoção de COT durante a regeneração após o experimento com 120 $\mathrm{mg} / \mathrm{L}$ de Cr (VI).
Gopalan e Veeramani (1994) obtiveram $41 \%$ de remoção de Carbono Orgânico Dissolvido (COD) de um afluente contendo 5 $\mathrm{mg} / \mathrm{L}$ de $\mathrm{Cr}$ (VI), utilizando um reator CSTR com TDH de 60-72 horas. Dermou et al (2005) utilizando um biofiltro "Trickling" aeróbio com cultura pura de Acinetobacter sp obtiveram $69 \%$ de remoção de COT em 24 horas de operação. A concentração de $\mathrm{Cr}$ (VI) no afluente foi de $30 \mathrm{mg} / \mathrm{L}$ e de COT de 390 $\mathrm{mg} / \mathrm{L}$.

Elangovan e Philip (2009) obtiveram uma eficiência de remoção de COT de $85 \%$, utilizando um reator contínuo de leito em suspensão, para um TDH de 48 horas e uma concentração de COT afluente de $3000 \mathrm{mg} / \mathrm{L} \mathrm{e}$ $20 \mathrm{mg} / \mathrm{L}$ de Cr (VI). Segundo esses autores, a concentração crítica de $\mathrm{Cr}$ (VI) que afeta a remoção de COT varia de 5 a $50 \mathrm{mg} / \mathrm{L}$.

Nos dois experimentos com cromo no meio foram verificados os seguintes aspectos: aumento do COT nas saídas dos biorreatores nas horas iniciais, maior eficiência de remoção durante a regeneração e ausência de crescimento celular significativo.

\section{CONCLUSÃO}

A remoção de COT no teste de referência foi maior do que a obtida nos experimentos com cromo no meio. Tal fato indica que pode ter ocorrido alterações no metabolismo celular e na microbiota, assim como o processo de bioacumulação do metal na parede celular bacteriana, fazendo com que os micro-organismos não consigam promover a quebra das ligações dos compostos presentes no meio, podendo o restante destas moléculas permanecerem intactas, resultando em pequenas variações do COT. A maior eficiência de remoção verificada durante a regeneração dos biorreatores também é um indício de que a presença de cromo no meio afeta a remoção de COT.

$\mathrm{O}$ aumento dos valores de COT nas saídas dos biorreatores no início dos experimentos contendo $\mathrm{Cr}$ (VI) ocorreu, provavelmente, devido à morte e lise celular, ocasionada pela presença do metal. Não foi verificado crescimento celular significativo, o que indica, também, que a atividade celular estava voltada para a remoção de cromo. 


\section{REFERÊNCIAS}

COMPANHIA DE TECNOLOGIA DE SANEAMENTO AMBIENTAL (CETESB): Curtumes. Secretaria do meio ambiente, São Paulo, 2009. In: http://www.cetesb.sp.gov.br/Agua/rios/ indice iap iqa.asp. Acesso em $\underline{04 / 05 / 2013}$.

DERMOU, E., VELISSARIOU, A., XENOS, D. VAYENAS, D.V (2005), Biological chromium (VI) reduction using a trickling filter. Journal of Hazardous Materials B126, p.78-85.

ELANGOVAN, R., PHILIP, L, CHANDRARAL, K (2009) Hexavalent Chromium Reduction by Free and Immobilized Cell-free Extract of Arthrobacter rhombi-RE. Biochem Biotechnol.

GEBARA, F (1999), Activated sludge biofilm wastewater treatment system. Water Research, v. $33 ; n^{\circ} 1$, p. 230-238.

GOPALAN, R., VEERAMANI, H (1994), Studies on microbial chromate reduction by Pseudomonas sp. in aerobic continuous suspended growth cultures. Biotechnology and Bioengineering, 43, 471476.

MÜLLER, N (1998), Implementing biofilm carriers into activated sludge process 15 years of experience._Water Science and Technology, 37, p. 167-174, 1998.

SANT ANNA JR., G. L, (2010) no prelo, Tratamento Biológico de Efluentes: Fundamentos e aplicações. 1 ed. Rio de Janeiro, Editora Interciência.

WOLFF, D. B., PAUL, E., COSTA, R, H, R. (2004), Reatores Híbridos: uma nova alternativa para o tratamento de efluentes. Saneamento Ambiental, v. 111, p. 30-33.

\section{AGRADECIMENTOS}

Os autores agradecem a Fapemig, Projeto TEC - APQ-00920-11 pelo apoio financeiro. 